\title{
miR-200c-3p regulates the proliferation and apoptosis of human trabecular meshwork cells by targeting PTEN
}

\author{
YIFEI SHEN, YIN ZHU and FEI RONG
}

\author{
Department of Ophthalmology, Wujiang First People's Hospital, Suzhou, Jiangsu 215200, P.R. China
}

Received December 24, 2018; Accepted December 9, 2019

DOI: $10.3892 / \mathrm{mmr} .2020 .11198$

\begin{abstract}
Glaucoma is an optic neuropathy that may lead to visual field loss and blindness. Human trabecular meshwork (HTM) cell dysfunction increases intraocular pressure, which leads to glaucoma. microRNAs (miRs) are single-stranded non-coding RNAs that regulate cellular processes in HTM cells. The aim of the present study was to evaluate the role of miR-200c-3p in HTM cells. HTM cells were treated with $300 \mu \mathrm{M} \mathrm{H}_{2} \mathrm{O}_{2}$, and the expression of miR-200c-3p was measured by reverse transcription-quantitative polymerase chain reaction. The expression of miR-200c-3p was significantly downregulated under oxidative stress. Phosphatase and tensin homolog (PTEN) was predicted to be a potential target of miR-200c-3p using TargetScan, and this was confirmed by a dual-luciferase reporter assay. The expression of PTEN was upregulated in $\mathrm{H}_{2} \mathrm{O}_{2}$-treated HTM cells. In addition, PTEN expression was negatively regulated by miR-200c-3p. Then, cell proliferation and apoptosis were measured by Cell Counting Kit- 8 and flow cytometry assays, respectively. The results demonstrated that the overexpression of miR-200c-3p enhanced cell proliferation and inhibited cell apoptosis, while PTEN reversed the effects of miR-200c-3p. In addition, miR-200c-3p suppressed the expression of PTEN, cleaved caspase- 3 and Bax, and improved the expression of phosphorylated (p)-AKT, AKT and p-serine/threonine-protein kinase mTOR (mTOR), while PTEN attenuated these effects. Taken together, these data suggested that overexpression of miR-200c-3p targets PTEN to suppress cleaved caspase-3 and Bax expression and activate the PTEN/AKT/mTOR signaling pathway, thereby resulting in the promotion of cell proliferation and the inhibition of cell apoptosis. These results revealed the role of miR-200c-3p in HTM cells and its underlying molecular mechanism, which may provide a potential target for the treatment of patients with glaucoma.
\end{abstract}

Correspondence to: Dr Yifei Shen, Department of Ophthalmology, Wujiang First People's Hospital, 3 Gongyuan Road, Wujiang, Suzhou, Jiangsu 215200, P.R. China

E-mail: shenyifei2018@aliyun.com

Key words: human trabecular meshwork cells, microRNA-200c-3p, phosphatase and tensin homolog, proliferation, apoptosis

\section{Introduction}

Glaucoma is the second leading cause of irreversible visual field loss and blindness in the world (1). The two most common types are primary open-angle glaucoma and primary angle-closure glaucoma (1). Pathological elevated intraocular pressure (IOP) is the major primary risk factor for glaucoma (2). Human trabecular meshwork (HTM) cells, at the irido-corneal angle, serve a critical role in regulating IOP (3). The anomalous accumulation of extracellular matrix (ECM) may induce dysfunction in aqueous humor outflow through HTM cells, thereby upregulating IOP, leading to the onset of glaucoma $(4,5)$. In addition, increases in IOP induce HTM deformation, while decreases in IOP restore the anatomy (6). Therefore, an improved understanding of the biological function of HTM cells may improve the understanding the pathogenesis of glaucoma.

MicroRNAs (miRNAs/miRs) are a class of single-stranded, non-coding, 22 nucleotide (nt)-long small RNAs (7), which are sequence-specific regulators of post-transcriptional gene expression (8). miRNAs are associated with the occurrence and development of disease, and they have been reported to exert a wide range of effects through regulating the biological processes of their associated genes (9). miRNAs are also involved in regulating the normal or pathophysiological cellular functions of HTM cell contraction and ECM turnover (10). miR-200c is one of the members of the miR-200 family, which is located at chromosome 12p13 (11). Previous data have revealed that miR-200c is downregulated in glaucoma (12). Furthermore, miR-200c may regulate trabecular contraction and modulate IOP (13). However, the role of miR-200c and its associated molecular mechanisms are largely unknown. Oxidative stress is a critical risk factor in glaucoma; antioxidant glutathione levels are decreased in patients with glaucoma (14), and it also has alterative effect on HTM cells, leading eventually to increased IOP $(15,16)$. Therefore, it is necessary to examine the effects of miR-200c in HTM cells under oxidative stress.

In the present study, to elucidate the role of miR-200c-3p in primary HTM cells, the expression of miR-200c-3p was detected in $\mathrm{H}_{2} \mathrm{O}_{2}$-treated HTM cells. Then the target gene of miR-200c-3p, phosphatase and tensin homolog (PTEN), was verified. Notably, overexpression of miR-200c-3p promoted cell proliferation and inhibited cell apoptosis by targeting PTEN. The results of the present study may suggest a potential target for HTM cells. 


\section{Materials and methods}

Cell culture and $\mathrm{H}_{2} \mathrm{O}_{2}$ treatment. HTM cells were purchased from ScienCell Research Laboratories, Inc. The cells were cultured in TM cell medium (TMCM) containing 2\% FBS (ScienCell Research Laboratories, Inc.), $1 \%$ TM cell growth supplements and $1 \%$ penicillin/streptomycin (ScienCell Research Laboratories, Inc.). The cells were maintained in a humidified incubator at $37^{\circ} \mathrm{C}$ with $5 \% \mathrm{CO}_{2}$.

HTM cells were seeded into 6-well plates at a density of $2 \times 10^{5}$ cells/well. The cells were treated at $37^{\circ} \mathrm{C}$ with $300 \mu \mathrm{M}$ $\mathrm{H}_{2} \mathrm{O}_{2}$ (Sigma-Aldrich; Merck KGaA) in serum-free medium for $2 \mathrm{~h}$. Then, the medium was removed and replaced with complete TMCM, and cells were then incubated for an additional $2 \mathrm{~h}$. These cells served as an oxidative stress model, and were named $\mathrm{H}_{2} \mathrm{O}_{2}$-HTM cells.

Target prediction and dual-luciferase reporter assay. The potential targets of miR-200c-3p were predicted using the bioinformatics analysis tool TargetScan (http://www.targetscan. org/vert_72) (17). A dual-luciferase reporter assay was then performed to confirm the prediction. The wild-type (WT) or mutant sequences of the PTEN 3' untranslated region (UTR), containing the predicted miR-200c-3p target site, were inserted into the pmirGLO vector (Promega Corporation), and named pmirGLO-WT-PTEN and pmirGLO-mutant-PTEN, respectively. A density of $2 \times 10^{5}$ cells/well $\mathrm{H}_{2} \mathrm{O}_{2}-\mathrm{HTM}$ cells were seeded in 24-well plates prior to transfection. A total of $24 \mathrm{~h}$ later, cells were co-transfected with pmirGLO-WT-PTEN or pmirGLO-mutant-PTEN and miR-200c-3p mimics or miR-NC mimics using Lipofectamine ${ }^{\circledR} 2000$ reagent (Invitrogen; Thermo Fisher Scientific, Inc.), according to the manufacturer's protocol. Firefly and Renilla luciferase activities were measured with a Dual-Glo Luciferase Assay System (Promega Corporation) at $48 \mathrm{~h}$ post-transfection. The results for luciferase activity were normalized to Renilla luciferase activity.

Cell transfection. miR-200c-3p mimics (5'-UAACACUGU CUGGUAAUGAUGUU-3') and negative control mimics (miR-NC mimics: 5'-UAACAC UGUCUGGUAAUG AUGUU-3') were designed and synthesized by Biomics Biotechnologies Co., Ltd. A total of $4 \times 10^{5} \mathrm{H}_{2} \mathrm{O}_{2}-\mathrm{HTM}$ cells/well were seeded in 6-well plates and transfected with $20 \mathrm{nM}$ miR-200c-3p mimics and miR-NC mimics in serum-free medium using Lipofectamine ${ }^{\circledR} 2000$ (Invitrogen; Thermo Fisher Scientific, Inc.). A total of $6 \mathrm{~h}$ later, the medium was replaced by complete medium. The cells were harvested for incubation at $37^{\circ} \mathrm{C}$ for $48 \mathrm{~h}$.

Reverse transcription-quantitative PCR (RT-qPCR). To detect the mRNA expression levels of miR-200c-3p, total RNA was extracted from the cells using a miRNeasy FFPE kit (Qiagen $\mathrm{GmbH}$ ), according to the manufacturer's protocol. Then, cDNA was synthesized using the miScript II RT kit (Qiagen $\mathrm{GmbH}$ ), according to the manufacturer's protocol. To detect PTEN expression, total RNA was extracted using TRIzol ${ }^{\circledR}$ reagent (Invitrogen; Thermo Fisher Scientific, Inc.), according to the manufacturer's protocol. The reverse transcription was performed with a Multiscribe Reverse Transcriptase kit (Invitrogen; Thermo Fisher Scientific, Inc.), according to the manufacturer's protocol. Expression of miRNAs and mRNAs was quantified using GoTaq qPCR Master mix (Promega Corporation), according to the manufacturer's protocol, on an ABI PRISM 7500 Real-Time PCR System (Applied Biosystems; Thermo Fisher Scientific, Inc.). The following qPCR thermocycling conditions were used for miR-200c-3p: Initial denaturation at $95^{\circ} \mathrm{C}$ for $2 \mathrm{~min}$; and 40 cycles of denaturation at $95^{\circ} \mathrm{C}$ for $5 \mathrm{sec}$, annealing at $55^{\circ} \mathrm{C}$ for $30 \mathrm{sec}$ and extension at $72^{\circ} \mathrm{C}$ for $30 \mathrm{sec}$. The following qPCR thermocycling conditions were used for PTEN: Initial denaturation at $95^{\circ} \mathrm{C}$ for $2 \mathrm{~min}$; and 40 cycles of denaturation at $95^{\circ} \mathrm{C}$ for $15 \mathrm{sec}$ and annealing and extension at $60^{\circ} \mathrm{C}$ for $1 \mathrm{~min}$. The sequences of the specific primers were as follows: miR-200c-3p forward, 5'-TCGTCTTACCCAGCAGTG-3' and reverse, 5'-CGGCAG TATTAGAGACTCC-3'; U6 forward, 5'-CTCGCTTCGGCA GCACATA-3' and reverse, 5'-AACGATTCACGAATTTGC GT-3'; PTEN forward, 5'-TTGAAGACCATAACCCACCAC AG-3' and reverse, 5'-CATTACACCAGTTCGTCCCTTTC-3'; and GAPDH forward, 5'-CTGGGCTACACTGAGCACC-3' and reverse, 5'-AAGTGGTCGTTGAGGGCAATG-3'. U6 was used as an internal control for miR-200c-3p and GAPDH was used as an internal control for PTEN. Data were analyzed using the $2^{-\Delta \Delta \mathrm{Cq}}$ method (18).

Western blot analysis. Protein was extracted from transfected cells in RIPA lysis buffer (Beyotime Institute of Biotechnology). The protein concentration was detected by BCA Protein Assay kit (Beyotime Institute of Biotechnology). Then, $30 \mu \mathrm{g}$ protein/lane was separated by $12 \%$ SDS-PAGE and transferred to a PVDF membrane (Beyotime Institute of Biotechnology). Following blocking with 5\% skim milk dissolved in TBS $+0.05 \%$ Tween-20 (TBST) for $1 \mathrm{~h}$ at room temperature, the membrane was incubated with the following primary antibodies (Abcam) at $4^{\circ} \mathrm{C}$ overnight: Anti-PTEN (cat. no. ab31392; 1:1,000), anti-AKT (cat. no. ab179463, 1:10,000), anti-phosphorylated (p)-AKT (cat. no. ab131443; 1:1,000), anti-serine/threonine-protein kinase mTOR (mTOR; cat. no. ab2732; 1:2,000), anti-p-mTOR (cat. no. ab109268; 1:1,000), anti-cleaved caspase-3 (cat. no. ab32042; 1:500), anti-Bax (cat. no. ab32503; 1:2,000) and anti-GAPDH (cat. no. ab9485; 1:2,500). Following washing with TBST, the membrane was incubated with a horseradish peroxidase-conjugated goat anti-rabbit IgG secondary antibody (cat. no. ab205718; 1:2,000; Abcam) for $1 \mathrm{~h}$ at room temperature. Immunoblotting signals were developed with an ECL Plus Western Blotting Substrate kit (Thermo Fisher Scientific, Inc.). The intensity of each band sample was analyzed with Image J v.1.49 software (National Institutes of Health).

Cell proliferation assay. Cell proliferation was measured using a Cell Counting Kit-8 (CCK-8; Dojindo Molecular Technologies, Inc.), following the manufacturer's protocol. Transfected cells were seeded in 96-well plates and incubated at $37^{\circ} \mathrm{C}$ with $5 \% \mathrm{CO}_{2}$ for $0,12,24$ and $48 \mathrm{~h}$. Following this, $10 \mu \mathrm{l} \mathrm{CCK}-8$ was added to each well and cells were incubated at $37^{\circ} \mathrm{C}$ for an additional $2 \mathrm{~h}$. The absorbance was measured at $450 \mathrm{~nm}$ using a microplate reader (BioTek Instruments, Inc.).

Cell apoptosis assay. Cell apoptosis levels were measured using an Annexin V-fluorescein isothiocyanate (FITC) Apoptosis 
Detection kit (eBioscience; Thermo Fisher Scientific, Inc.), according to the manufacturer's protocol. Briefly, a total of $5 \times 10^{5}$ transfected cells/well were seeded in 6 -well plates. A volume of $5 \mu \mathrm{l}$ Annexin V-FITC and $10 \mu \mathrm{l}$ propidium iodide (PI) were added into each well and the cells were incubated in the dark for $15 \mathrm{~min}$ at room temperature. The apoptotic cells were detected using a FACSCanto II flow cytometer (BD Biosciences). Data analysis was performed with Cell Quest Pro software (v5.1; BD Biosciences).

Statistical analysis. All statistical analyses were performed using GraphPad Prism 7 software (GraphPad Software, Inc.). Differences between two groups were analyzed by Student's t-test, and differences among multiple groups were analyzed by one-way analysis of variance followed by Student-Newman-Keuls post hoc analysis. All data are presented as the mean \pm SEM of $\geq 3$ independent experimental repeats. $\mathrm{P}<0.05$ was considered to indicate a statistically significant difference.

\section{Results}

miR-200c-3p is downregulated in HTM cells under oxidative stress. To investigate the role of miR-200c-3p, its expression was first measured in HTM cells and $\mathrm{H}_{2} \mathrm{O}_{2}$-HTM cells using RT-qPCR. As demonstrated in Fig. 1, compared with control group, the expression of miR-200c-3p was significantly decreased in HTM cells treated with $\mathrm{H}_{2} \mathrm{O}_{2}(\mathrm{P}<0.01)$.

PTEN is a target of $m i R-200 c-3 p$. miR-200c-3p was predicted to be able to bind with the 3'-untranslated region (UTR) of PTEN at position 2,516-2,522 nt by TargetScan (Fig. 2A). To confirm the prediction, $\mathrm{H}_{2} \mathrm{O}_{2}$-HTM cells were co-transfected with pmirGLO-WT-PTEN or pmirGLO-mutant-PTEN and miR-200c-3p mimics or miR-NC mimics. As demonstrated by the detection of luciferase activity, compared with the miR-NC mimics, the miR-200c-3p mimics evidently inhibited the luciferase activity when co-transfected with pmirGLO-WT-PTEN $(\mathrm{P}<0.01)$. However, there was no significant difference between miR-200c-3p and miR-NC mimics when combined with pmirGLO-mutant-PTEN (Fig. 2B). These results suggested that PTEN is a target of miR-200c-3p.

Expression of PTEN is upregulated in HTM cells under oxidative stress. Following treatment of the HTM cells with $\mathrm{H}_{2} \mathrm{O}_{2}$, the expression of the target gene PTEN was measured by RT-qPCR. As indicated in Fig. 3A, PTEN expression was greatly increased in $\mathrm{H}_{2} \mathrm{O}_{2}$-HTM cells, compared with HTM cells in the control group $(\mathrm{P}<0.01)$. In addition, the western blot analysis results demonstrated that the protein level of PTEN was also increased under $\mathrm{H}_{2} \mathrm{O}_{2}$ treatment $(\mathrm{P}<0.01$; Fig. 3B).

miR-200c-3p promotes cell proliferation and inhibits cell apoptosis, while PTEN reverses the effect of miR-200c-3p. To investigate the role of miR-200c-3p and PTEN in $\mathrm{H}_{2} \mathrm{O}_{2}-\mathrm{HTM}$ cells, the cells were transfected with miR-200c-3p mimics, miR-NC mimics, and the transfection efficiency was then evaluated by RT-qPCR. miR-200c-3p expression was markedly increased in cells post transfection of miR-200c-3p

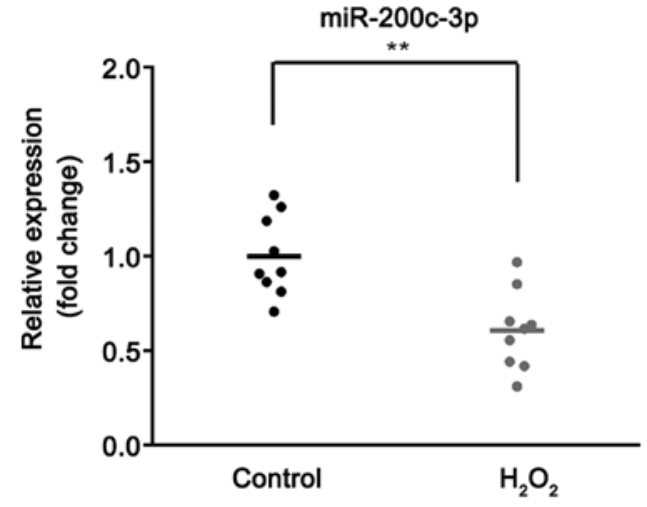

Figure 1. Expression of miR-200c-3p is downregulated in HTM cells following treatment with $\mathrm{H}_{2} \mathrm{O}_{2}$. The expression was measured in HTM cells and $\mathrm{H}_{2} \mathrm{O}_{2}$-HTM cells by reverse transcription-quantitative polymerase chain reaction. Data are presented as the mean \pm standard error of the mean. ${ }^{* *} \mathrm{P}<0.01$. miR, microRNA; HTM, human trabecular meshwork.
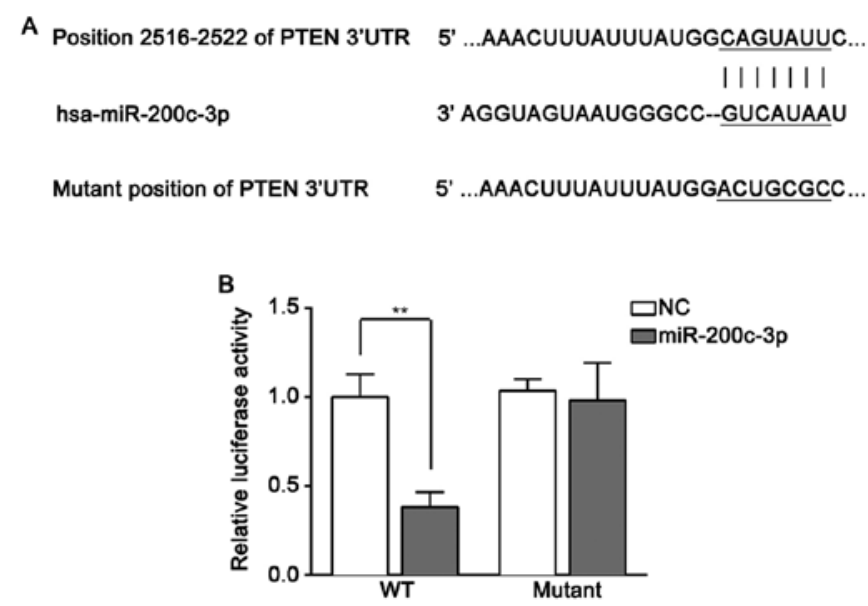

Figure 2. PTEN is identified as a target gene of miR-200c-3p. (A) TargetScan predicted the binding site of the seed region of miR-200c-3p in the 3'UTR of PTEN. (B) The dual-luciferase reporter assay verified the prediction. The luciferase activity was measured in $\mathrm{H}_{2} \mathrm{O}_{2}$-HTM cells co-transfected with pmirGLO-WT-PTEN or pmirGLO-mutant-PTEN and miR-NC mimics or miR-200c-3p mimics. Data are presented as the mean \pm standard error of the mean. ${ }^{* *} \mathrm{P}<0.01$. UTR, untranslated region; PTEN, phosphatase and tensin homolog; WT, wild-type; NC, negative control; HTM, human trabecular meshwork; miR, microRNA; UTR, untranslated region; hsa, Homo sapiens.

mimics, compared with the miR-NC mimics and control groups $(\mathrm{P}<0.01$; Fig. $4 \mathrm{~A})$. Then, it was identified that the overexpression of miR-200c-3p induced the downregulation of PTEN ( $\mathrm{P}<0.01$; Fig. $4 \mathrm{~B}$ and $\mathrm{C})$. These results indicated that PTEN expression was negatively regulated by miR-200c-3p. Furthermore, cell proliferation and cell apoptosis were measured in HTM cells under oxidative stress by CCK- 8 and flow cytometry assays, respectively. For cell proliferation, miR-200c-3p enhanced cell proliferation compared with the miR-NC mimics group $(\mathrm{P}<0.01)$. Overexpression of PTEN attenuated cell proliferation compared with the miR-200c-3p mimics group $(\mathrm{P}<0.01)$. However, there was no significant difference between the miR-NC group and the miR-200c-3p mimics + pcDNA3.1 PTEN group (Fig. 5A). By contrast, the overexpression of miR-200c-3p reduced cell apoptosis, while PTEN abolished this inhibition $(\mathrm{P}<0.01$; Fig. 5B and $\mathrm{C})$. 
A

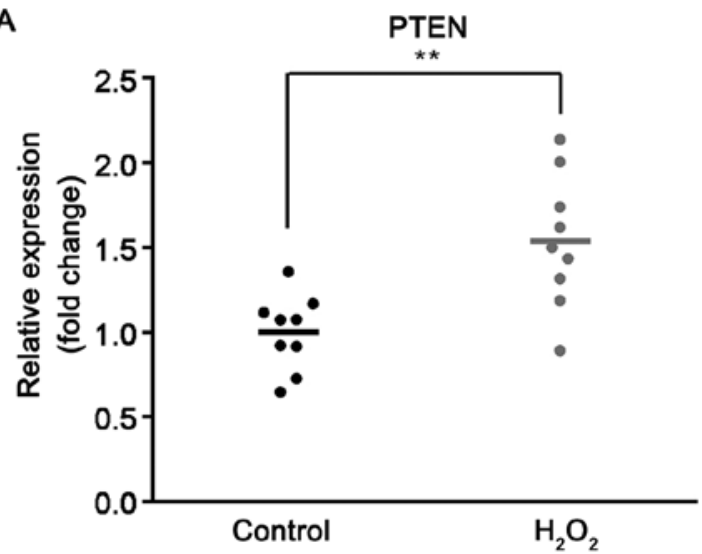

B

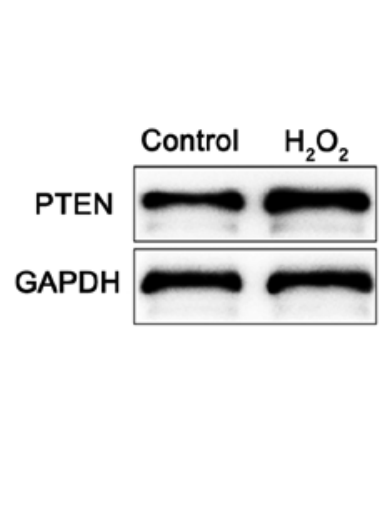

PTEN

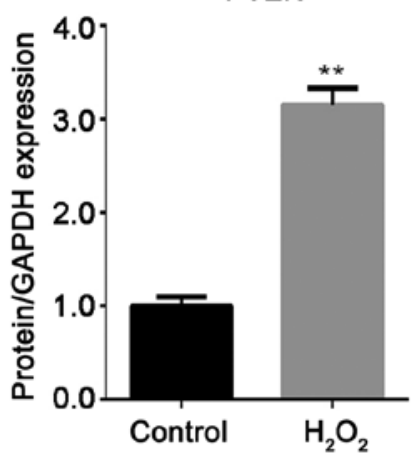

Figure 3. $\mathrm{H}_{2} \mathrm{O}_{2}$ treatment induces increased PTEN expression levels in HTM cells. (A) The mRNA expression of PTEN was examined by reverse transcription-quantitative polymerase chain reaction in HTM cells and $\mathrm{H}_{2} \mathrm{O}_{2}-\mathrm{HTM}$ cells. (B) The protein level of PTEN was measured in HTM cells with or without $\mathrm{H}_{2} \mathrm{O}_{2}$ treatment. GAPDH was used for normalization. Data are presented as the mean \pm standard error of the mean. ${ }^{* *} \mathrm{P}<0.01$. HTM, human trabecular meshwork; PTEN, phosphatase and tensin homolog.

A

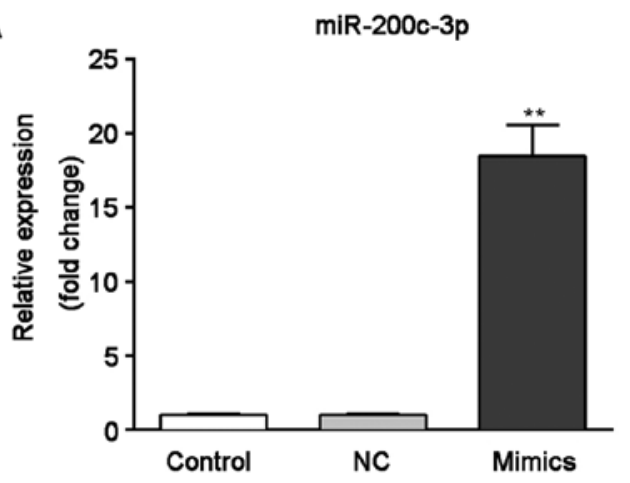

B

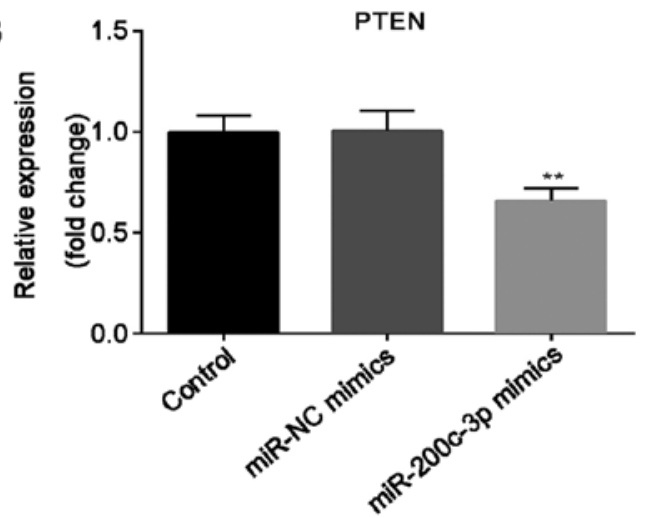

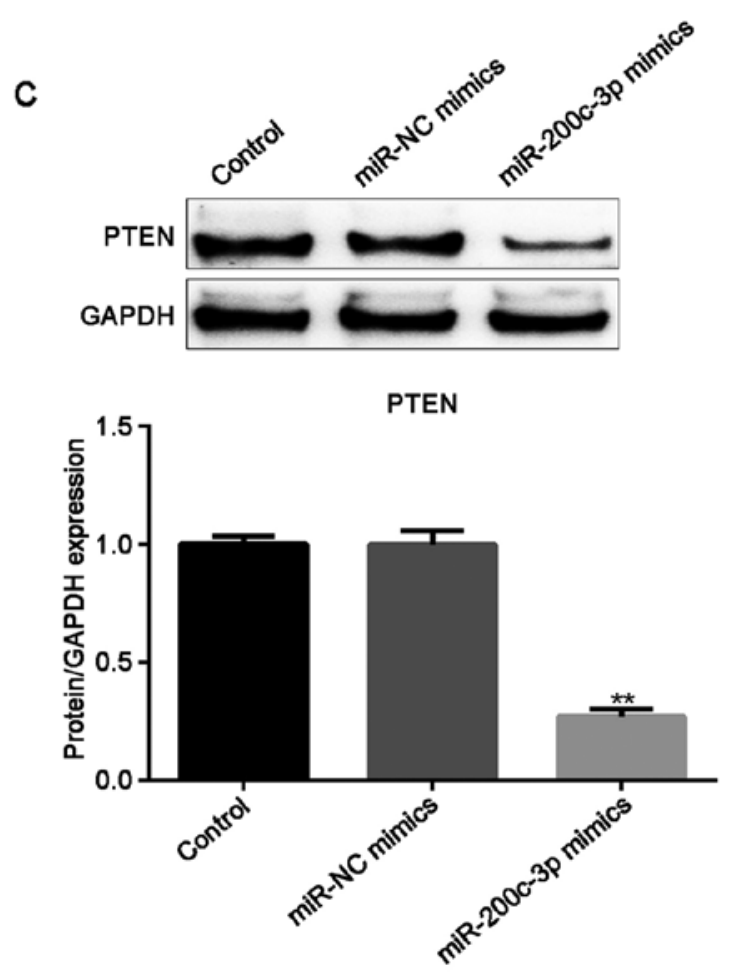

Figure 4. PTEN expression is negatively regulated by miR-200c-3p. (A) miR-200c-3p was overexpressed in the cells following transfection with the miR-200c-3p mimic. (B) The expression of PTEN was detected using reverse transcription-quantitative polymerase chain reaction in $\mathrm{H}_{2} \mathrm{O}_{2}-\mathrm{HTM}$ cells transfected with miR-NC mimics and miR-200c-3p mimics. (C) The protein expression levels of PTEN were examined when miR-200c-3p was overexpressed. GAPDH was used as a loading control. The relative expression of PTEN was quantified. Data are presented as means \pm standard error of the mean. ${ }^{* *} \mathrm{P}<0.01$. HTM, human trabecular meshwork; miR, microRNA; PTEN, phosphatase and tensin homolog; NC, negative control. 
A

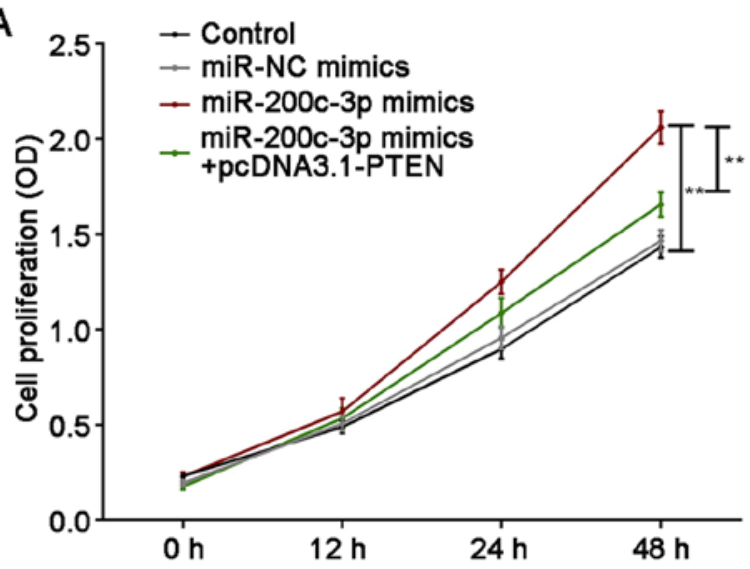

B

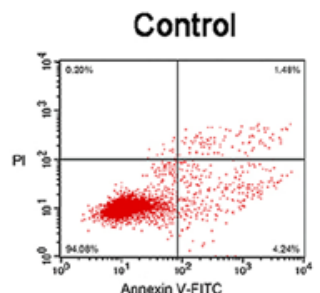

miR-200c-3p mimics

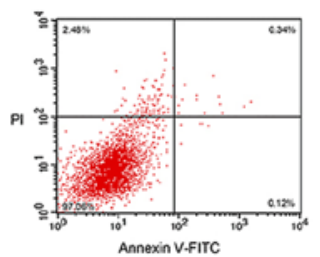

miR-NC mimics

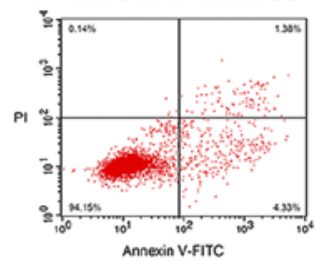

miR-200c-3p mimics

+ pcDNA3.1-PTEN

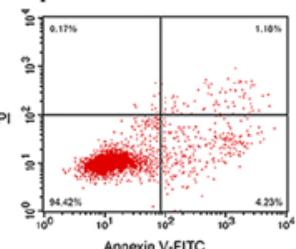

C

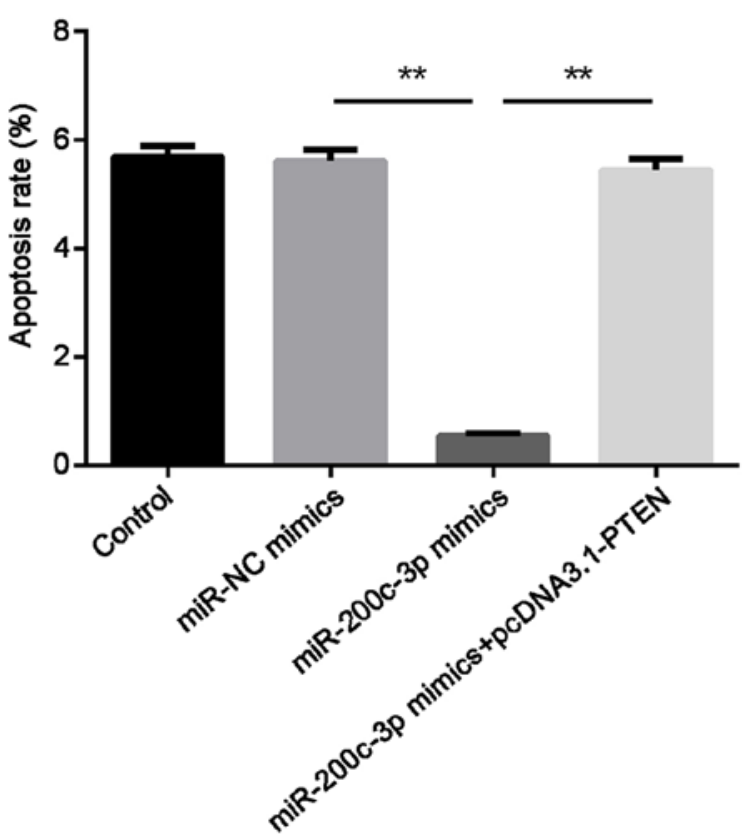

Figure 5. Overexpression of miR-200c-3p leads to the promotion of cell proliferation and suppression of cell apoptosis. (A) Cell proliferation was measured in the $\mathrm{H}_{2} \mathrm{O}_{2}-\mathrm{HTM}$ cells following transfection for $0,12,24$ and $48 \mathrm{~h}$, using a Cell Counting Kit-8 assay. (B) Cell apoptosis was measured by flow cytometry. (C) The percentage of apoptotic cells was quantified. Data are presented as the mean \pm standard error of the mean. ${ }^{* *} \mathrm{P}<0.01$. miR, microRNA; HTM, human trabecular meshwork; NC, negative control; PTEN, phosphatase and tensin homolog; OD, optical density.

These results suggested that miR-200c-3p promoted cell proliferation and suppressed cell apoptosis by targeting PTEN.

Overexpression of miR-200c-3p suppresses the expression of cleaved caspase-3 and Bax, and activates the PTEN/AKT/mTOR signaling pathway by targeting PTEN. Finally, the expression of PTEN, cleaved caspase-3, Bax, AKT, p-AKT, mTOR and p-mTOR at the protein level was measured by western blot analysis. The results demonstrated that overexpressed miR-200c-3p suppressed the expression of PTEN, cleaved caspase- 3 and $\mathrm{Bax}(\mathrm{P}<0.01)$, while PTEN overexpression reversed the suppression induced by miR-200c-3p mimics $(\mathrm{P}<0.01)$. In addition, miR-200c-3p upregulated the protein expression of $\mathrm{p}-\mathrm{AKT}$ and $\mathrm{p}-\mathrm{mTOR}(\mathrm{P}<0.01)$, while the overexpression of PTEN reversed the effect of miR-200c-3p $(\mathrm{P}<0.01)$. However, miR-200c-3p did not have an effect on total AKT and mTOR expression (Fig. 6A and B). These results suggested that miR-200c-3p targeted PTEN to suppress the expression of cleaved caspase- 3 and Bax, and activated the PTEN/AKT/mTOR signaling pathway.

\section{Discussion}

In the present study, miR-200c-3p was identified to be downregulated in HTM cells under oxidative stress. Overexpression of miR-200c-3p significantly promoted cell proliferation, inhibited cell apoptosis, suppressed the expression of cleaved caspase- 3 and Bax, and activated the PTEN/AKT/mTOR pathway, while overexpression of PTEN reversed the effects of miR-200c-3p.

Greater resistance to aqueous humor outflow through the HTM increases IOP and causes glaucoma (4). Oxidative stress is a risk factor in glaucoma and one of the cellular factors that results in alterations in the $\operatorname{HTM}(14,15)$. In addition, oxidative stress treatment may lead to the changes in miRNA 

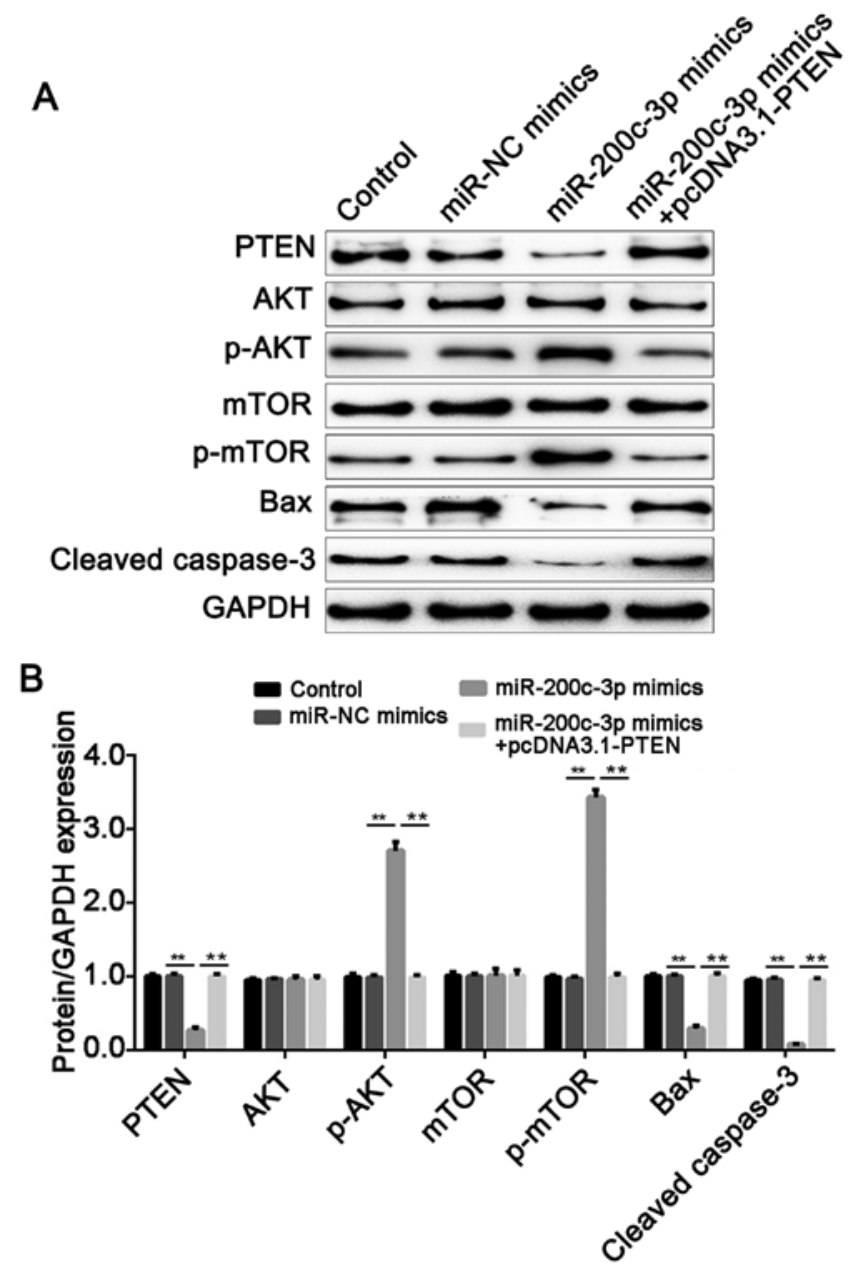

Figure 6. miR-200c-3p decreases the expression of PTEN, cleaved caspase-3, Bax, p-AKT and p-mTOR, while PTEN abolishes the effect induced by miR-200c-3p mimics. (A) The protein expression of PTEN, cleaved caspase-3, Bax, AKT, p-AKT, mTOR and p-mTOR was measured by western blot analysis. GAPDH was used as an internal control. (B) Densitometric analysis of the western blot analysis grey values. Data are presented as means \pm standard error of the mean. ${ }^{* *} \mathrm{P}<0.01$. miR, microRNA; p-, phosphorylated; PTEN, phosphatase and tensin homolog; mTOR, serine/threonine-protein kinase mTOR; $\mathrm{NC}$, negative control.

expression; for example, $\mathrm{H}_{2} \mathrm{O}_{2}$ increased miR-200c expression levels in human umbilical vein endothelial cells (19). Additionally, miR-181a levels in $\mathrm{H}_{2} \mathrm{O}_{2}$-treated HTM cells were decreased (20). miR-200c is a well-known tumor suppressor, which has been studied primarily in the context of tumor development, proliferation, metastasis and therapy resistance (21). However, little is known about the role of miR-200c in HTM cells. A previous study revealed that the expression levels of miR-200c were upregulated in HTM cells (22) and downregulated in glaucoma (12). Furthermore, miR-200c inhibits the contraction of HTM cells and leads to decrease in IOP $(10,13)$. In the present study, miR-200c-3p was highly expressed in HTM cells, and oxidative stress induced a downregulation of the expression. However, the underlying molecular mechanism of miR-200c-3p in HTM cells is not clear.

The bioinformatics analysis results from the present study indicated that PTEN is a potential target of miR-200c-3p, and a dual-luciferase reporter assay verified the prediction. PTEN has lipid and protein activities (23). A tumor suppresser, PTEN is also associated with neurodegeneration, and deletion of PTEN has been demonstrated to lead to axonal regeneration following optic nerve injury (24). In addition, PTEN is the target of miR-93-5p, which regulates the autophagy of retinal ganglion cells in NMDA-induced glaucoma (25). However, to the best of our knowledge, there is little known about PTEN in HTM cells. A previous study revealed that oxidative stress may increase cellular PTEN levels (26). Similarly, in the present study, it was also identified that the expression of PTEN was upregulated in HTM cells following treatment with $\mathrm{H}_{2} \mathrm{O}_{2}$; its expression was the opposite of that of miR-200c-3p.

Oxidative stress serves a critical role in promoting HTM cell apoptosis, and it is reportedly triggered following the alteration of trabecular meshwork tissue function and integrity, which is caused by mitochondrial damage $(27,28)$. Several miRNAs have been suggested to regulate HTM cell viability or apoptosis; for example, miR-181a enhanced HTM cell viability and inhibited cell apoptosis induced by $\mathrm{H}_{2} \mathrm{O}_{2}$ (20). Upregulation of miR-1298 markedly suppressed chronic oxidative stress-induced apoptosis in HTM cells (5). Additionally, inhibition of miR-93 increased cell viability and suppresses cell apoptosis in glaucoma HTM cells (29). miR-200c and PTEN are both factors involved in regulating cell apoptosis $(30,31)$. The present study demonstrated that the level of PTEN was negatively regulated by miR-200c-3p. In addition, miR-200c-3p promoted cell proliferation and inhib- 
ited cell apoptosis in HTM cells by targeting PTEN. These results suggested that miR-200c-3p serves as an anti-apoptotic factor and PTEN serves a role as a pro-apoptotic factor in $\mathrm{H}_{2} \mathrm{O}_{2}$-treated HTM cells.

Apoptosis-associated modulator Bax (pro-apoptotic) is expressed in both HTM cells and ex-vivo tissues (32). Bax is required for oxidative stress-induced cell death (33). In addition, cleaved caspase-3, an activated form of caspase 3 , exhibits negative responses to oxidative stress (34). The expression of PTEN has the same variation trend as that of Bax and cleaved caspase-3 (35). In the PTEN/AKT/mTOR signaling axis, the PI3K-AKT signaling pathway is one of the major pathways in HTM cells responding to oxidative stress (34). PTEN is a key modulator involved in the PI3K signaling pathway, which negative regulates phosphorylated AKT (36). AKT phosphorylates and activates mTOR, one of the downstream targets (37). In the present study, miR-200c-3p suppressed Bax and cleaved caspase-3 levels, and increased the phosphorylation of AKT and mTOR in H2O2-HTM cells, while PTEN attenuated these effects. The aforementioned results indicated that overexpression of miR-200c-3p suppressed Bax and cleaved caspase-3, and activated the PTEN/AKT/mTOR signaling pathway via targeting PTEN in HTM cells under oxidative stress.

In conclusion, overexpression of miR-200c-3p enhanced and inhibited cell proliferation and apoptosis, respectively, by suppressing cleaved caspase-3 and Bax expression and activating the PTEN/AKT/mTOR signaling pathway by targeting PTEN. The present study revealed the role of miR-200c-3p in $\mathrm{H}_{2} \mathrm{O}_{2-}$ treated HTM cells, and also assessed the molecular mechanism underlying miR-200c-3p. These data may provide an improved understanding of HTM cells and provide a therapeutic target for glaucoma.

\section{Acknowledgements}

Not applicable.

\section{Funding}

No funding was received.

\section{Availability of data and materials}

The datasets used and/or analyzed during the current study are available from the corresponding author on reasonable request.

\section{Authors' contributions}

YS designed the study wrote the manuscript, whereas YZ and FR performed the experiments and analyzed the data. All authors read and approved the final manuscript.

\section{Ethics approval and consent to participate}

Not applicable.

\section{Patient consent for publication}

Not applicable.

\section{Competing interests}

The authors declare that they have no competing interests.

\section{References}

1. Mantravadi AV and Vadhar N: Glaucoma. Prim Care 42: 437-449, 2015.

2. Nickells RW, Howell GR, Soto I and John SW: Under pressure: Cellular and molecular responses during glaucoma, a common neurodegeneration with axonopathy. Annu Rev Neurosci 35: 153-179, 2012.

3. Stamer WD and Clark AF: The many faces of the trabecular meshwork cell. Exp Eye Res 158: 112-123, 2017.

4. Porter K, Hirt J, Stamer WD and Liton PB: Autophagic dysregulation in glaucomatous trabecular meshwork cells. Biochim Biophys Acta 1852: 379-385, 2015.

5. Ruibin W, Zheng X, Chen J, Zhang X, Yang X and Lin Y: Micro RNA-1298 opposes the effects of chronic oxidative stress on human trabecular meshwork cells via targeting on EIF4E3. Biomed Pharmacother 100: 349-357, 2018.

6. Johnstone MA: The aqueous outflow system as a mechanical pump: Evidence from examination of tissue and aqueous movement in human and non-human primates. J Glaucoma 13: 421-438, 2004.

7. Bartel DP: MicroRNAs: Genomics, biogenesis, mechanism, and function. Cell 116: 281-297, 2004.

8. Pillai RS: MicroRNA function: Multiple mechanisms for a tiny RNA? RNA 11: 1753-1761, 2005.

9. Guo R, Shen W, Su C, Jiang S and Wang J: Relationship between the pathogenesis of glaucoma and miRNA. Ophthalmic Res 57: 194-199, 2017.

10. Gonzalez P, Li G, Qiu J, Wu J and Luna C: Role of microRNAs in the trabecular meshwork. J Ocul Pharmacol Ther 30: 128-137, 2014.

11. Feng X, Wang Z, Fillmore R and Xi Y: MiR-200, a new star miRNA in human cancer. Cancer Lett 344: 166-173, 2014.

12. Romano GL, Platania CB, Forte S, Salomone S, Drago F and Bucolo C: MicroRNA target prediction in glaucoma. Prog Brain Res 220: 217-240, 2015.

13. Luna C, Li G, Huang J, Qiu J, Wu J, Yuan F, Epstein DL and Gonzalez P: Regulation of trabecular meshwork cell contraction and intraocular pressure by miR-200c. PLoS One 7: e51688, 2012.

14. Kimura A, Namekata K, Guo X, Noro T, Harada C and Harada T: Targeting oxidative stress for treatment of glaucoma and optic neuritis. Oxid Med Cell Longev 2017: 2817252, 2017.

15. Zhao J, Wang S, Zhong W, Yang B, Sun L and Zheng Y: Oxidative stress in the trabecular meshwork (Review). Int J Mol Med 38: 995-1002, 2016.

16. Saccà SC, Gandolfi S, Bagnis A, Manni G, Damonte G, Traverso CE and Izzotti A: The outflow pathway: A tissue with morphological and functional unity. J Cell Physiol 231: 1876-1893, 2016

17. Agarwal V, Bell GW, Nam JW and Bartel DP: Predicting effective microRNA target sites in mammalian mRNAs. Elife 4, 2015.

18. Livak KJ and Schmittgen TD: Analysis of relative gene expression data using real-time quantitative PCR and the 2(-Delta DeltaC(T)) method. Methods 25: 402-408, 2001.

19. Carlomosti F, D'Agostino M, Beji S, Torcinaro A, Rizzi R, Zaccagnini G, Maimone B, Di Stefano V, De Santa F, Cordisco S, et al: Oxidative stress-induced miR-200c disrupts the regulatory loop among SIRT1, FOXO1, and eNOS. Antioxid Redox Signal 27: 328-344, 2017.

20. Wang Y, Zhou H, Liu X, Han Y, Pan S and Wang Y: MiR-181a inhibits human trabecular meshwork cell apoptosis induced by $\mathrm{H} 2 \mathrm{O} 2$ through the suppression of NF- $\mathrm{KB}$ and JNK pathways. Adv Clin Exp Med 27: 577-582, 2018.

21. Mutlu M, Raza U, Saatci Ö, Eyüpoğlu E, Yurdusev E and Sahin Ö: miR-200c: A versatile watchdog in cancer progression, EMT, and drug resistance. J Mol Med (Berl) 94: 629-644, 2016.

22. Li G, Luna C, Qiu J, Epstein DL and Gonzalez P: Alterations in microRNA expression in stress-induced cellular senescence. Mech Ageing Dev 130: 731-741, 2009.

23. Milella M, Falcone I, Conciatori F, Cesta Incani U, Del Curatolo A, Inzerilli N, Nuzzo CM, Vaccaro V, Vari S, Cognetti F and Ciuffreda L: PTEN: Multiple functions in human malignant tumors. Front Oncol 5: 24, 2015. 
24. Koriyama Y, Kamiya M, Arai K, Sugitani K, Ogai K and Kato S Nipradilol promotes axon regeneration through S-nitrosylation of PTEN in retinal ganglion cells. Adv Exp Med Biol 801: 751-757, 2014.

25. Li R, Jin Y, Li Q, Sun X, Zhu H and Cui H: MiR-93-5p targeting PTEN regulates the NMDA-induced autophagy of retinal ganglion cells via AKT/mTOR pathway in glaucoma. Biomed Pharmacother 100: 1-7, 2018.

26. Leslie NR, Bennett D, Lindsay YE, Stewart H, Gray A and Downes CP: Redox regulation of PI 3-kinase signalling via inactivation of PTEN. EMBO J 22: 5501-5510, 2003.

27. Yu AL, Fuchshofer R, Kampik A and Welge-Lüssen U: Effects of oxidative stress in trabecular meshwork cells are reduced by prostaglandin analogues. Invest Ophthalmol Vis Sci 49: 4872-4880, 2008

28. Saccà SC, Pulliero A and Izzotti A: The dysfunction of the trabecular meshwork during glaucoma course. J Cell Physiol 230: 510-525, 2015.

29. Wang Y, Li F and Wang S: MicroRNA-93 is overexpressed and induces apoptosis in glaucoma trabecular meshwork cells. Mol Med Rep 14: 5746-5750, 2016.

30. Yuan C, Xu M, Rong R, Mei Y, Cai W, Li L, Xue Y,Zhu B, Sun K and Han L: miR-200c regulates endothelin-1 induced PASMCs abnormal proliferation and apoptosis. IUBMB Life 69: 877-886, 2017.

31. Li MF, Guan H and Zhang DD: Effect of overexpression of PTEN on apoptosis of liver cancer cells. Genet Mol Res 15, 2016.
32. Baleriola J, García-Feijoo J, Martínez-de-la-Casa JM, Fernández-Cruz A, de la Rosa EJ and Fernández-Durango R: Apoptosis in the trabecular meshwork of glaucomatous patients. Mol Vis 14: 1513-1516, 2008

33. Steckley D, Karajgikar M, Dale LB, Fuerth B, Swan P, Drummond-Main C, Poulter MO, Ferguson SS, Strasser A and Cregan SP: Puma is a dominant regulator of oxidative stress induced Bax activation and neuronal apoptosis. J Neurosci 27: 12989-12999, 2007.

34. Awai-Kasaoka N, Inoue $\mathrm{T}$, Kameda $\mathrm{T}$, Fujimoto $\mathrm{T}$, Inoue-Mochita $\mathrm{M}$ and Tanihara $\mathrm{H}$ : Oxidative stress response signaling pathways in trabecular meshwork cells and their effects on cell viability. Mol Vis 19: 1332-1340, 2013.

35. Han Z, Chen F, Ge X, Tan J, Lei P and Zhang J: miR-21 alleviated apoptosis of cortical neurons through promoting PTEN-Akt signaling pathway in vitro after experimental traumatic brain injury. Brain Res 1582: 12-20, 2014.

36. Chalhoub $\mathrm{N}$ and Baker SJ: PTEN and the PI3-kinase pathway in cancer. Annu Rev Pathol 4: 127-150, 2009.

37. Chen JS, Wang Q, Fu XH, Huang XH, Chen XL, Cao LQ, Chen LZ, Tan HX, Li W, Bi J and Zhang LJ: Involvement of $\mathrm{PI} 3 \mathrm{~K} / \mathrm{PTEN} / \mathrm{AKT} / \mathrm{mTOR}$ pathway in invasion and metastasis in hepatocellular carcinoma: Association with MMP-9. Hepatol Res 39: 177-186, 2009. 